\title{
Opinions of patients with rheumatoid arthritis about their own functional capacity: how valid is it?
}

\author{
J W G Jacobs, F G J Oosterveld, N Deuxbouts, J J Rasker, E Taal, J Dequeker, \\ R Uytterhoeven
}

\begin{abstract}
Self assessment health status questionnaires are increasingly used to measure health status or the effect of treatment in patients with rheumatoid arthritis (RA). Most of these questionnaires measure functional (physical) disabilities. The question arises, however, as to how well self assessment questionnaires reflect the true functional status of patients or whether they only reflect their imaginary functional capacities. How valid is the opinion of patients with RA about their own functional capacity?
\end{abstract}

To answer this question an investigation was performed in 80 patients with RA. Forty Dutch and 40 Belgian patients with RA completed the functional items of the DUTCH-AIMS, the Dutch version of the Arthritis Impact Measurement Scales (AIMS), a self assessment questionnaire specific to arthritis. Their scores on the functional scales were compared with the scores on the same scales completed by two experienced physiotherapists after evaluation of the functional ability of these patients. This was achieved by observing the patients perform the tasks given in the questionnaire. Correlation coefficients between the scores of the patients and the physiotherapists were highly significant for all the scales. No significant differences were found between the patients' and physiotherapists' mean scale scores except for the mobility scale in the Dutch patients. The strength of agreement (Cohen's $x$ ) of most scale scores of the patients and physiotherapists was substantial. The estimates of the overall functional capacity (the mean of the five scale scores) of the Belgian and Dutch patients show high correlations between the patients and the physiotherapists.

It is concluded that patients' opinion about their functional ability is valid in that it is in agreement with their real functional abilities. This study provides further evidence for the validity of the DUTCH-AIMS as a measure of functional disability and health status in Dutch and Belgian patients with RA.

It is difficult to assess the health status or the effect of treatment in patients with rheumatoid arthritis (RA). Common measures such as joint count and erythrocyte sedimentation rate (ESR) address disease activity more than outcome. In the past few years several self assessment arthritis outcome and health status instruments have been developed. ${ }^{1}$ Some of these mainly measure functional (physical) disabilities. Health status according to the WHO definition includes physical, psychological, and social components of life. Measurement of arthritis specific health status is performed by the Arthritis Impact Measurement Scales (AIMS), a self administered questionnaire created and validated by Meenan et al. $^{2-4}$ The AIMS has proved to be valid in assessing the outcome of various treatments and programmes in patients with various rheumatic diseases. $^{5-7}$ The Dutch version of the AIMS, the DUTCH-AIMS, has been validated in Dutch patients with RA. ${ }^{8}$ Significant correlations were found between scores on the scales of the DUTCH-AIMS, haemoglobin, ESR, self assessment of functional impairment, and perceived overall health; the internal consistency of the scales was satisfactory.

One question about the functional ability measured by this kind of self assessment questionnaire remains to be answered: how valid is the opinion of patients with RA about their own functional capacity? How sure can we be that self assessment questionnaires do not measure the patients' imaginary function? In finding statistically significant correlations between scores on the functional scales of self assessment questionnaires and the American Rheumatism Association (ARA) functional class, this question is not sufficiently answered, because the ARA functional class is a coarse measure. Moreover, for systematic over- or underestimation the same significant correlations could be found. In this paper we describe an investigation into the validity of patients' opinion about their own functional capacities.

\section{Patients and methods}

Forty consecutive Dutch and 40 Dutch-speaking Belgian patients with definite or classical rheumatoid arthritis were asked to complete the items of the five functional scales of the DUTCH-AIMS: mobility, physical activity, dexterity, household activity, and activities of daily living (see table 1 ). ${ }^{9}$

Immediately afterwards a physical examination was performed by a experienced physiotherapist (F G J O for the Dutch and N D for the Belgian patients) who observed the patients perform the functional activities referred to in the questionnaire. The physiotherapists were not allowed to see the patients' questionnaires, nor to discuss the patients' performance of the functional activities. Following this, the items 
Table 1 Activities of the functional scales of the DUTCH-AIMS (key words)

\begin{tabular}{l} 
Mobility \\
Travelling around \\
Public transport \\
Having to stay indoors \\
Having to stay in bed or chair \\
Dexterity \\
Write with pen/pencil \\
Button articles/clothing \\
Turn key in lock \\
Tie a pair of shoes \\
Open a new jar of food \\
Activities of daily living \\
Taking a bath/shower \\
Getting dressed \\
Using the toilet \\
Getting out of bed/chairs \\
Physical activity \\
Vigorous activities \\
Walking blocks/climbing a few flights of stairs \\
Bending, lifting, or stooping \\
Walking one block/climbing one flight of stairs \\
Walking aids/assistance \\
Household activity \\
Shopping \\
Preparing meals \\
Doing housework \\
Doing laundry \\
Taking medicine \\
Handling money \\
Using a telephone \\
\hline
\end{tabular}

Table 2 Study population data. There was no significan difference between Belgian and Dutch patients in any measurable parameter

\begin{tabular}{lcc}
\hline & $\begin{array}{c}\text { Belgian } \\
\text { patients }\end{array}$ & $\begin{array}{c}\text { Dutch } \\
\text { patients }\end{array}$ \\
\hline Number of patients & 7 & 10 \\
Men & 33 & 30 \\
Women & $59(9)$ & $59(9)$ \\
Mean (SD) age (years) & $39-80$ & $41-75$ \\
Range (years) & $9(8)$ & $15(11)$ \\
Mean (SD) duration of RA (years) & $0-44$ & $1-47$ \\
Range (years) & & \\
Rheumatoid factor & 31 & 32 \\
Positive & 9 & 8 \\
Negative & & \\
ARA classification & 13 & 9 \\
Definite RA & 27 & 31 \\
Classical RA & & \\
Functional class & & 1 \\
I & 2 & 28 \\
II & 18 & 2 \\
III & 13 & \\
IV & 7 & \\
\hline
\end{tabular}

of the functional scales of the DUTCH-AIMS were completed by the physiotherapists, applying the results of the physical investigation and functional tests.

The patients' scores on the scales, ranging from 0 to 10,0 representing good health status and 10 the worst status, were compared with the scale scores of the physiotherapist. Correlations were determined with Pearson's correlation coefficient; for the concordance between the patients' and physiotherapists' scores Cohen's weighted $x$ was calculated. ${ }^{10}$ The values of $x$ can be described as follows: the range $0 \cdot 21-0 \cdot 40$ indicates fair, $0.41-0.60$ moderate, $0.61-0.80$ substantial, and 0.81-1.00 (almost) perfect strength of agreement. ${ }^{10}$ The mean scores of the scales were compared using $t$ tests. The level of statistical significance $(\alpha)$ was $0 \cdot 05$. For classification purposes the ARA grading and the functional classification were assessed. ${ }^{11}$ Rheumatoid factor was also measured using the Rose-Waaler test (positive when $\geqslant 1 / 32$ ) or a nephelometric assay (IgM rheumatoid factor, positive when $>60 \mathrm{U} / \mathrm{l}$ ) were used.

\section{Results}

Table 2 summarises the clinical data of the 80 patients. There are no significant differences between the 40 Belgian and 40 Dutch patients with respect to the clinical data and scale scores. Table 3 shows the scale scores of the patients and the physiotherapists with the correlation coefficients. The mean scale scores of the patients and physiotherapists do not differ significantly except the score on the mobility scale in the Dutch patients. Correlations between the scores of the physiotherapists and the patients are highly statistically significant. Concordance $(x)$ in four of the five scales is 'substantial' in the Belgian patients and in three scales in the Dutch patients. Figures 1 and 2 show the overall physical capacity of the individual patients as the mean of the five scale scores with the patients' overall score plotted against that of the physiotherapist. The results show good agreement between the scores of the patients and

Table 3 Scores on the functional scales of the DUTCH-AIMS. Range of all scales 0-10, 10 representing the worst condition

\begin{tabular}{|c|c|c|c|c|c|}
\hline & $\begin{array}{l}\text { Patients' } \\
\text { score }\end{array}$ & $\begin{array}{l}\text { Physiotherapists } \\
\text { score }\end{array}$ & $\begin{array}{l}\text { Difference } \\
\text { between scores: } \\
\text { (confidence limits } \\
\text { of difference } \\
\text { between scores) }\end{array}$ & $\begin{array}{l}\text { Pearson's } \\
\text { correlation } \\
\text { coefficient }\end{array}$ & $\begin{array}{l}\text { Cohen's } \\
\text { weighted } x\end{array}$ \\
\hline $\begin{array}{l}\text { Belgian patients } \\
\text { Mean (SE) mobility } \\
\text { Range (25-75 centile) } \\
\text { Mean (SE) physical activity } \\
\text { Range (25-75 centile) } \\
\text { Mean (SE) dexterity } \\
\text { Range (25-75 centile) } \\
\text { Mean (SE) household activity } \\
\text { Range ( } 25-75 \text { centile) } \\
\text { Mean (SE) activities of daily living } \\
\text { Range (25-75 centile) }\end{array}$ & $\begin{array}{l}3 \cdot 1(0 \cdot 5) \\
0-10(0-5) \\
6 \cdot 5(0 \cdot 4) \\
0-10(4-8) \\
6 \cdot 4(0 \cdot 5) \\
0-10(4-10) \\
2 \cdot 4(0 \cdot 3) \\
0-6 \cdot 2(0 \cdot 8-3 \cdot 9) \\
2 \cdot 2(0 \cdot 4) \\
0-7 \cdot 5(0-3 \cdot 8)\end{array}$ & $\begin{array}{l}3 \cdot 1(0 \cdot 6) \\
0-10(0-7 \cdot 5) \\
6 \cdot 2(0 \cdot 5) \\
0-10(4-8) \\
6 \cdot 4(0 \cdot 5) \\
0-10(4-10) \\
2 \cdot 4(0 \cdot 3) \\
0-6 \cdot 2(0 \cdot 8-3 \cdot 9) \\
2 \cdot 6(0 \cdot 4) \\
0-7 \cdot 5(0-5)\end{array}$ & $\begin{array}{r}-0.03(-0.8 / 0 \cdot 7) \\
0.3(-0.2 / 0 \cdot 8) \\
0.1(-0.6 / 0 \cdot 7) \\
-0.02(-0.4 / 0 \cdot 4) \\
-0.3(-0.8 / 0 \cdot 2)\end{array}$ & $\begin{array}{l}0.76 \\
0.84 \\
0.82 \\
0.76 \\
0.78\end{array}$ & $\begin{array}{l}0.68 \\
0.71 \\
0.69 \\
0.61 \\
0.56\end{array}$ \\
\hline $\begin{array}{l}\text { Dutch patients } \\
\text { Mean (SE) mobility } \\
\text { Range ( } 25-75 \text { centile) } \\
\text { Mean (SE) physical activities } \\
\text { Range (25-75 centile) } \\
\text { Mean (SE) dexterity } \\
\text { Range (25-75 centile) } \\
\text { Mean (SE) household activity } \\
\text { Range (25-75 centile) } \\
\text { Mean (SE) activities of daily living } \\
\text { Range (25-75 centile) }\end{array}$ & $\begin{array}{l}3 \cdot 6(0 \cdot 6) \\
0-10(0-6 \cdot 2) \\
6 \cdot 9(0 \cdot 4) \\
2-10(6-8) \\
6 \cdot 4(0 \cdot 5) \\
0-10(4-10) \\
3 \cdot 1(0 \cdot 3) \\
0-7 \cdot 7(1 \cdot 5-4 \cdot 6) \\
2 \cdot 1(0 \cdot 3) \\
0-6 \cdot 3(0-3 \cdot 8)\end{array}$ & $\begin{array}{l}7 \cdot 2(0 \cdot 3) \\
5-10(5-9 \cdot 3) \\
6 \cdot 8(0 \cdot 3) \\
2-10(6-8) \\
6 \cdot 5(0 \cdot 5) \\
2-10(4-10) \\
3 \cdot 0(0 \cdot 3) \\
0-9 \cdot 2(1 \cdot 5-3 \cdot 9) \\
1 \cdot 9(0 \cdot 4) \\
0-7 \cdot 5(0-4 \cdot 4)\end{array}$ & $\begin{array}{c}-3.6(-2.7 /-4.4) \\
0.1(-0.3 / 0.5) \\
-0.2(-1.0 / 0.7) \\
0.04(-0.3 / 0.4) \\
0.1(-0.4 / 0.6)\end{array}$ & $\begin{array}{l}0.69 \\
0.81 \\
0.62 \\
0.88 \\
0.76\end{array}$ & $\begin{array}{l}0.16 \\
0.66 \\
0.47 \\
0.70 \\
0.63\end{array}$ \\
\hline
\end{tabular}

${ }^{*}$ All differences not statistically significant except between the scores on the mobility scale in the Dutch situation; $p<0 \cdot 0001$. tAll correlation coefficients are significant at $p<0 \cdot 0001$. 


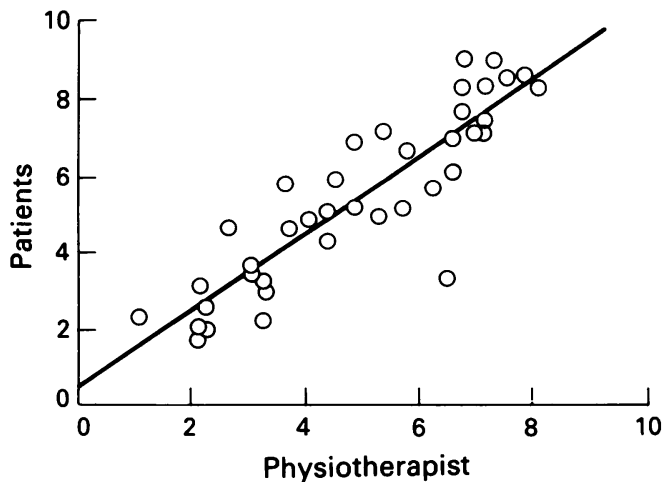

Figure 1 Overall functional scores of the individual Dutch patients: patients' scores versus physiotherapist's scores. Each dot represents the functional capacity of one patient $(n=40)$. Pearson's r: 0.88, $p<0.0001$.

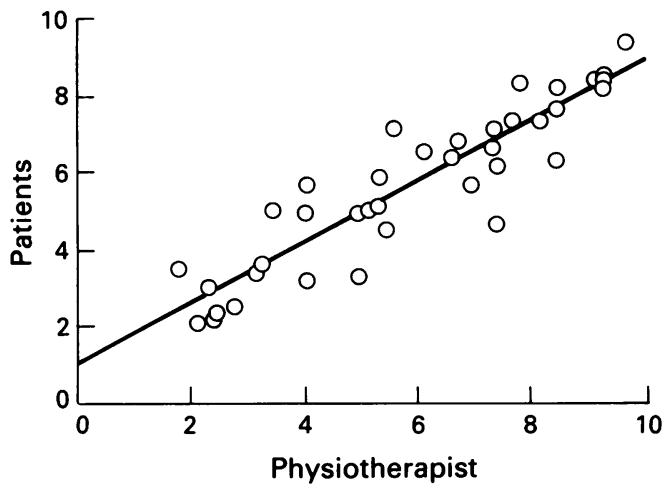

Figure 2 Overall functional scores of the individual Belgian patients: patients' scores versus physiotherapist's scores. Each dot represents the functional capacity of one patient $(n=40)$. Pearson's $r: 0.92, p<0.0001$.

physiotherapists over the whole range of the overall functional capacity score. The differences between the scores of the patients and physiotherapists do not vary much across the range of the overall physical scores.

\section{Discussion}

The results of this study indicate that patients' opinion about their functioning is valid. The statistically significant difference between the mean score of the Dutch patients and the physiotherapist on the mobility scale combined with the good correlation of the scores on this scale indicates that the Dutch physiotherapist's judgement of the mobility of patients in general was less optimistic than the judgement of the Dutch patients themselves. The Dutch physiotherapist, in contrast to his Belgian colleague, did not ask the patients to perform all the tasks of the moblity scale, but he estimated mobility on the basis of overall physical examination. This will probably have contributed to this disagreement.

In the Belgian and Dutch patients, all with definite or classical RA, the ARA classification and functional class are comparable, as are the scale scores, indicating that the nationality of the patients did not have an important influence on the scale scores.

The items in the dexterity scale caused some patients difficulty in interpreting the expression 'easily' in four of the five questions. For this reason changing these questions may be considered. For example, 'Can you easily write with a pen or pencil?' with answering alternatives 'yes' or 'no' could be changed into 'Can you write with a pen or pencil?' with the possible answers 'yes', 'yes, with some difficulty', and 'no'. The validity of the altered questions would probably be unchanged but this should be investigated.

Several self assessment questionnaires have been developed for the measurement of functional capacity. Of these instruments, the AIMS, the Stanford Health Assessment Questionnaire (HAQ), and the Sickness Impact Profile have been extensively validated. ${ }^{1}$ These instruments have also been translated and validated in many ways in several languages and countries. So, for example, investigations such as those described here, comparing observed abilities with the patients' scores on a questionnaire, have been performed with the HAQ and modified versions of the HAQ in the United Kingdom and in The Netherlands, showing that this questionnaire also measures patients' real function. ${ }^{12-15} \mathrm{We}$ chose to validate a version of the AIMS, the DUTCH-AIMS. The advantages of the use of a translated and validated version of an international well known instrument compared with a national questionnaire is that its interpretation is generally known and therefore easier to use. Furthermore, international comparisons of populations of patients with rheumatic diseases is probably facilitated.

In conclusion, our investigation shows that the opinion of Dutch and Belgian patients with RA about their functional ability is valid in that it is in agreement with their real functional abilities. This study provides further evidence for the validity of the DUTCH-AIMS as a measure of functional disability and health status in these patients.

We thank Francis S Walker, MD, PhD, for advice about the English and $M$ Boers, MD, PhD, for his useful suggestions about Cohen's $x$.

1 Liang M H, Larson M G, Cullen K E, Schwartz J A. Comparative measurement efficiency and sensitivity of five health status instruments for arthritis research. Arthritis Rheum 1985; 5: 542-7.

2 Meenan R F, Gertman P M, Mason J H. Measuring health status in arthritis; the Arthritis Impact Measuremen Scales. Arthritis Rheum 1980; 23: 146-52.

3 Meenan R F, Gertman P M, Mason J H, Dunaif R. The Arthritis Impact Measurement Scales; further investigations of a health status measure. Arthritis Rheum 1982; 25 1048-53.

4 Mason J H, Anderson J J, Meenan R F. A model of health status for rheumatoid arthritis; a factor analysis of the Arthritis Impact Measurement Scales. Arthritis Rheum 1988; 31: 714-20.

5 Meenan R F, Anderson J J, Kazis L E, et al. Outcome assessment in clinical trials. Evidence for the sensitivity of a health status measure. Arthritis Rheum 1984; 27: 1344-52.

6 Anderson J J, Firschein H E, Meenan R F. Sensitivity of a health status measure of short-term clinical changes in health status measure of short-term clin
arthritis. Arthritis Rheum 1989; 32: 844-50.

7 Kazis L E, Anderson J J, Meenan R F. Effect sizes for interpreting changes in health status. Med Care 1989; 27 (suppl): 178-89. 
8 Taal E, Jacobs J W G, Rasker J J, Seydel E, Wiegman O. Evaluation of the DUTCH Arthritis Impact Measurement Scales (DUTCH-AIMS) in patients with rheumatoid arthritis. Br $\mathcal{F}$ Rheumatol 1989; 28: 487-91.

9 Ropes M W, Bennet C A, Cobb S, Jacox R, Jessar R D. Revision of diagnostic criteria for rheumatoid arthritis. Ann Rheum Dis 1959; 18: 49-53.

10 Kramer M S, Feinstein A R. Clinical biostatistics LIV. The biostatistics of concordance. Clin Pharmacol Ther 1981; 29. 111-23.

11 Steinbrocker O, Traeger C H, Batterman R C. Therapeutic criteria in rheumatoid arthritis. $\mathcal{F} A M A$ 1949; 17: 453-8.

12 Sullivan F M, Eagers R C, Lynch K, Barber J H. Assessmen of disability caused by rheumatic diseases in general practice. Ann Rheum Dis 1987; 46: 598-600.

13 Kirwan J R, Reeback J S. Stanford Health Assessmen questionnaire modified to assess disability in British patients with rheumatoid arthritis. Br 7 Rheumatol 1986 25: 206-9.

14 Siegert C E H, Vleming L J, Vandenbroucke J P, Cats A Measurement of disability in Dutch rheumatoid arthritis Measurement of disability in Dutch rheumatoid arthritis

15 Bijlsma J W J, Oude Heuvel C H B, Zaalberg A. Development and validation of the Dutch questionnaire capacities of daily life (VDF) for patients with rheumatoid arthritis. f Rehabil Sci 1990; 3: 71-4. 